\title{
Entrevista con Gabriel Ignácio Anitua
}

Tamires Maria Alves e Gabriela Laura Gusis

\section{Gabriel Ignacio Anitua}

Es Defensor Público Oficial ante los Tribunales Orales en lo Criminal de la Ciudad de Buenos Aires. Es abogado licenciado en derecho y sociología por la Universidad de Buenos Aires. Realizó el Máster en "Sistema Penal y Problemas Sociales" por la Universidad de Buenos Aires. También tiene diploma de Estudios avanzados en Derecho Penal por la Universidad del País Vasco (1999) y defendió su doctorado el 2003 en la Universidad de Barcelona. Es autor de extensa bibliografía, y la mayoría de sus obras discurre sobre temáticas relacionadas al derecho penal destacándose su gran obra "Historias de los pensamientos criminológicos" traducida por la Editora Revan. ORCID: http://orcid.org/0000-0001-5182-6417 


\section{Entrevistadoras ( Tamires Alves e Gabriela Gusis) :}

Buenas tardes Gabriel. Vamos a empezar esta entrevista con vos hablando un poco de política. En los últimos años tanto acá en Argentina cuánto en Brasil tuvimos gobiernos dichos más progresistas, de izquierda y así mismo tuvimos el fenómeno del aumento de las prisiones. ¿Vos que piensas de eso? ¿No es divergente de nuestros teóricos de la criminología como Rusche y Kirchheimer o Wacquant a respecto del aumento de las prisiones cuando reducimos las inversiones sociales?

\section{Gabriel Anitua:}

Es un fenómeno complejo que, a muchos de los formados en criminología crítica o en posiciones progresistas, nos preocupa y además nos sorprende. Hay algunos trabajos ya hechos en ese sentido como Máximo Sozzo que comparó no solo en Argentina y Brasil sino en otros lugares como Ecuador y Venezuela ese mismo fenómeno para intentar explicarlo también. Además, no tiene que ver solo con la orientación ideológica sino también con un cierto bienestar económico, que también parece ir en contra de las tesis más tradicionales de la izquierda de asociar mayor explotación, o las tesis más antiguas de Rusche y Kircheimer, que parecen también en ese sentido contrario. Probablemente estos gobiernos más progresistas tampoco se escaparon a una nueva orientación del capitalismo que necesita crear clases subalternas que sean claramente identificables, aunque sean minoritarias. Eso pasa también en esos gobiernos que extienden cierto bienestar a sectores de clase media y baja, pero siempre tiene que haber algún sector de auténticos excluidos, que es la población de las prisiones. Es complejo de observar, incluso viendo lo contrario, pienso ahora más en Estados Unidos y Europa en períodos de recesión y con gobiernos más neoliberales o de derecha que reducen las tasas carcelarias o las paran, en el caso de Estados Unidos. También eso es confuso decir, y aquí incluso no se cumple la tesis de Rusche. Por eso es importante estudiar e intentar saber que pasa además de la intervención, también hay que hacer algo y frenar y denunciar ese fenómeno. Pero primero hay que intentar estudiar, explicarlo, saber qué pasa. Ver que no es necesariamente la consecuencia del aumento de las prisiones. Muchas veces tiene que ver con no presentar flancos a la crítica de la derecha. Estoy pensando sobre todo en Argentina que es muy complejo el sistema político y claro, en Brasil también. La derecha quizás tiene más fácil frenar el aumento de la punitividad porque no tiene una oposición que va a sacar votos con esa demagogia punitiva. Pienso también en Chile que es otro caso que con un gobierno progresista subió la tasa de reclusos y con la derecha de Piñera se frenó o incluso se bajó. ¿Claro, quien le va a ganar esa agenda a la derecha en Chile? La izquierda no. En cambio, al revés sí. Eso puede explicar también ese fenómeno. Pero es muy complejo, estoy pensando hipótesis sin comprobarlas. Habría que intentar evaluar, comprobar, y ver que es lo que se puede hacer para reducir ese fenómeno que en Brasil ya alcanza cifras más que preocupantes y esto es un auténtico genocidio, incluso. Esto es, de la población reclusa, la población que está con pedidos de captura y las que están en prisiones domiciliares, es enorme la población controlada o controlable en Brasil. Por lo tanto debo decir que hay trabajos, como esa investigación comparada que hizo Sozzo y que incluso demuestra que no todo es linear, el caso de Argentina también como se paró ese crecimiento de la población reclusa en 2004 y 2005 por un tiempo, al menos, después lo siguió creciendo. O el caso de Ecuador, que, con unas políticas claras de amnistía, de indulto generalizado por tema de drogas también bajaron bastante, pero luego siguieron subiendo. Esa lógica del punitivismo pareciera ir en América Latina más allá de izquierda o derecha, progresismo o no, bienestar o malestar económico. Parece 
una lógica que se impuso, yo creo que en los años 1990, y aunque a veces frena ya está marcando nuestros países.

\section{Entrevistadoras:}

$\mathrm{Si}$, es eso. Porque tenemos una lógica de desarrollo en esos gobiernos, entonces hay inversiones en la cuestión social. Todavía seguimos aumentando muchísimo el número de prisiones. Incluso, más que Estados Unidos y China que son los dos países en los primeros lugares del ranking de aprisionamientos.

\section{Gabriel Anitua:}

Sí, es preocupante. Además, esto sumado ahora con gobiernos reaccionarios, más de derecha empeora porque ya tienen ese gran número $y$, probablemente, imponen peores condiciones de vida en las prisiones. Pienso en el caso argentino que aumentaban el número de presos, pero al menos en el discurso había intentos de mejorar las situaciones de las cárceles. Ahora no, nadie piensa en construir más cárceles o mejorar la alimentación, ni los estudios, ni los derechos sociales en las propias cárceles. Por lo tanto, eso va a ser más duro, va a ser cualitativamente peor, no solo cuantitativamente. Entonces no se empeoran solamente por el aumento del número sino también por las condiciones materiales ¿De qué cárceles estamos hablando? Son cárceles peores.

\section{Entrevistadoras:}

Ahora estamos enfrentando los gobiernos actuales acá en Argentina con Macri, en Brasil con Temer y en Chile con Piñera, que son gobiernos más de derecha y tienen políticas públicas de seguridad más problemáticas. Y en esos últimos tiempos Patrícia Bullrich en Argentina habló de la doctrina Chocobar como buena, donde la policía podría defenderse, no siendo siempre culpable, diciendo que las acciones son de legítima defensa. Mientras que hay jóvenes como Facundo que murió en Tucumán con 11 años, Raphael Nahuel, joven mapuche muerto recién también. Y En Brasil empezamos ahora la intervención militar y otras políticas públicas que permiten que las actuaciones policiales sean absueltas mientras matan a los jóvenes. ¿Qué piensas de este momento que estamos viviendo?

\section{Gabriel Anitua:}

Yo intentaría no generalizar, creo que el problema es diferente. Decir que es siempre de derecha y que el marco económico similar, Piñera, Temer y Macri, justamente en materia de políticas concretas y políticas de seguridad, y políticas de seguridad emplazadas en lugar concreto, bueno, ahí seguramente hay diferencias. En el caso de Chile, por ejemplo, hay probablemente un capitalismo más hegemónico, no hay disputas dentro de la propia coalición dominante y por lo tanto pueden hacer políticas más coherentes. Como decía antes pueden reducir el número de presos, pueden hacer una reforma judicial y policial también, dirigida con una orientación. Esto en Brasil es mucho más complejo, en Río es un claro ejemplo y Argentina también. Porque dentro de esa coalición dominante hay también disputas. El problema no es solo los gobiernos de derecha que quieren hacer tal cosa y nos oponemos los que estamos más cercanos a la idea progresista. No. Esa coalición de derecha tiene muchas posiciones que están en contra. En Argentina es muy clara la disputa entre sectores vinculados a los servicios de inteligencia, sectores que se entregan al auto gobierno de la policía, que quizás Bullrich responda a esto, sectores que intentan la reforma más liberal y que están más cercanos al Ministerio de la Justicia. Hay entre ellos enormes disputas que son seguramente para ellos más importantes que las críticas que les podremos hacer 
desde la academia o de sectores de la oposición. En Brasil también pasa esto y este es un problema, porque, entonces sí que puede haber más muertos, más violencia y más incoherencia si se llevan más adelante esas políticas. El ejemplo más claro es el desgraciado hecho de ayer en Río de Janeiro. Una luchadora de derechos humanos, una política que es asesinada. ¿Por quién es asesinada? Esto hay que saberlo también para intentar decirles a quienes están en las posiciones dominantes "bueno, por lo menos hagan lo que sea el mal, pero háganlo bien a ese mal" porque puede haber disputas entre la policía y el ejército y eso va a tener bajas, va a tener muertes en nosotros. En eso lo que dice Raúl Zafaroni es muy cierto, es decir "cuidado porque los muertos los ponemos nosotros". Hay que ser cautelosos, exigir, incluso, cuando hagan esas políticas marcadas por el neoliberalismo, por ideas represivas o de derecha que lo hagan con cuidado, que lo hagan bien. Porque los muertos siempre son de los sectores más comprometidos, de los sectores populares, y normalmente los que menos cuentan, que son los pobres, los que no tienen nombre. No son solo los que vos mencionaste, hay muchas víctimas todos los días. $Y$ eso mucho tiene que ver con esas incoherencias de llevar adelante políticas. Y me parece que para criticarlas está bien bajar, decir "bueno aquí hay un problema en la política en Rio de Janeiro del uso de armas de la policía. Encarguémonos de eso." Creo que cuanto más pequeño mejor. Porque si vamos a criticar la política del neoliberalismo, vamos a estar todos de acuerdo en eso, pero no vamos a cambiar el día a día, por ejemplo, de la actuación policial, además en este caso del ejército en Brasil. Vamos a intentar ser concretos y la exigencia que le podemos hacer a este caso a los gobiernos, y hay que aguantarlos hasta que se vayan, es que por lo menos dirijan a sus subalternos, a los distintos actores, que no sean improvisados en llevar adelante las políticas, aunque estas no nos gusten. Es un temor grande a esto, sobre todo en Brasil y Argentina. También en Chile, pero tiene que ver que es un país más pequeño, unitario. Nuestros países son muy complejos porque hay muchas fuerzas al ser repúblicas federales, fuerzas policiales en guerras con otras, jueces con otros, hay muchos actores y eso es muy complejo. No hay que simplificar. No hay que decir "ah la culpa toda es del gobierno de Temer y del neoliberalismo". Bueno, en este caso quizás. En el gobierno Temer tal vez haya unos más malos que otros, pero mejor que estén estos a cargo de todas las fuerzas policiales y no policías matándose entre sí. Y sobre todo que no estén matando a pobres y negros.

\section{Entrevistadoras:}

En Argentina ustedes tuvieron el caso de desaparición de Santiago Maldonado, un joven que luchaba por la causa mapuche el 2017 y nosotros tuvimos caso de Amarildo el 2013, un hombre negro, que vivía en una favela en Brasil. ¿Qué podemos pensar al respecto de vivir en estados que son democráticos pero que tienen esas desapariciones típicas de estados de excepción ?

\section{Gabriel Anitua:}

Me parece que algo positivo que podemos sacar de esa experiencia es la reacción, incluso popular, contra ese suceso de desaparición luego aparición con la perdida de la vida de Santigo Maldonado. Hubo un rechazo casi mayoritario yo diría, la gente salió a la calle, se preocupó. Eso es bueno para marcarle en primer lugar el gobierno, pero también las concretas fuerzas, en ese caso la gendarmería. A los policiales les decimos "Bueno, no todo se puede. Vamos a estar atentos. Vamos a protestar. Vamos a relacionarlos a eso tipo de violencia, aún en un gobierno democrático, con las violencias de las dictaduras". Eso me parece lo positivo. Lo negativo es que se atrevan a hacer eso. Se atreven a hacerlo con esa legitimación que le da, en el caso argentino la gendarmería, en varios años en los cuales se mostraba como algo diferente a la 
policía. ¿Por qué? Porque no eran corruptos, entonces, pueden hacer cualquier cosa. Eso está cayendo, en parte por ese compromiso en este caso de la fuerza que estamos hablando de la gendarmería con el gobierno actual. Ya están haciendo cualquier cosa y pierden incluso ese prestigio que tenían en las clases populares vinculados a la no corrupción. Lo negativo tiene que ver con el respaldo que les da el gobierno. El respaldo que le da al autogobierno, policial o del ejercito y la gendarmería. El gobierno como que reconoce "no, yo aquí no puedo hacer nada" aunque en los anteriores les decían no, no sancionaba a nadie, lo apartaban de la fuerza, iniciaban una investigación. Estos gobiernos como qué, expresamente, y forma parte de sus discursos decir "nosotros vamos a aguantar lo que sea que haga la policía. La policía es nuestra policía, la gendarmería es nuestra gendarmería, lo que hacen está bien". Esto es lo más negativo y lo más peligroso porque es aumentar ese autogobierno. El autogobierno de la fuerza policial no es producto de Temer, de Macri o de la derecha, siempre estuvo en todas las democracias. Pero esto lo legitima de alguna manera, es decir "ustedes hagan lo que quieran que nosotros los vamos a apoyar siempre. Nunca habrá investigación" Esto es lo más peligroso de esos episodios de que mencionas y también de la doctrina Chocobar.

Pobre policía este Chocobar, se hizo famoso con esa expresión tan terrible que tiene que ver con la actuación de este hombre que mató por la espalda la persona que huía. Pero sobre todo tiene que ver con lo que hizo la ministra Bullrich y en parte también el presidente Macri al decir "incluso esto que todo el mundo ve por la televisión y que parece insostenible del derecho y de cualquier investigación imparcial de la justicia, incluso esto nosotros vamos a dar el aval. Incluso esto nosotros vamos a soportar porque la policía es el bien y los ladrones son en mal". Entonces autorizan incluso hasta la pena de muerte extrajudicial. Eso tiene una gravedad de los discursos de los derechos. Eso es el anti derecho, que la ministra de seguridad y el presidente avalen eso tiene un alcance terrible. Este discurso, como digo, del Estado de derecho, pero también de lo que está diciendo a las policías. Está diciendo "pueden hacer cualquier cosa" y de hecho tuvimos ejemplos posteriores. El chico ese, Facundo asesinado en Tucumán hace pocos días y varios hechos que pueden vincularse a la policía si le dan permiso. Estamos recibiendo el mensaje. Un mensaje que es siempre tramposo por parte de los políticos utilitarios porque los que van a apoyar ahora, pero mañana si tienen que usar a un policía como fusible, se le van a usar. Pero los policías no hacen ese análisis tan agudo. Si escuchan que los comunicadores sociales y los políticos les dicen: "Muy bien! Aplauso que han matado a un delincuente". Bueno, esto lo van hacer, lo van a replicar. Esto me parece de lo más peligroso, esa consecuencia concreta, material de permiso para no respetar los derechos humanos, para matar directamente.

\section{Entrevistadoras:}

$\mathrm{Si}$, claro. Y todavía lo que más espanta es el resultado final, con eso quiero decir, lo que más oímos en las calles son "Nosotros queremos a los bandidos presos y muertos. Ustedes quienes defienden a los bandidos. Ustedes quienes son a favor de los derechos humanos quienes están todo el tiempo defendiendo a los tipos malos". Y no es de eso que estamos hablando. Creemos que los derechos humanos están mal, tanto para la policía y sus familias cuanto para los ciudadanos comunes y principalmente para los más pobres. Sobre todo, con esa cobertura mediática terrible donde los medios de comunicación están para culpabilizar a determinados individuos. 


\section{Gabriel Anitua:}

Exactamente. No sé el caso de Brasil, pero en Argentina creo que hay larvada una resistencia en el discurso de la democracia. Muchas personas que habían apoyado a la dictadura militar y que durante años se mantuvieron ocultas porque es una vergüenza, porque no podría decirse y ahora se atreven a decir "este discurso de derechos humanos fue lo que posibilitó condenar a estos militares y hasta civiles que colaboraron y a eso no estamos de acuerdo". Y ahora son capaces de decir eso. No creo que todos los gobiernos y todas las coaliciones de derecha, todos los votantes comparten de esas ideas. Pero quienes tienen esas ideas se sienten representados por ese gobierno y se atreven a hacer cosas y a decir cosas que antes, ni lo que sea por vergüenza, no las decían. Y así han cosas. Eso me parece también muy preocupante ahora. En el caso de Brasil sé que es más complejo porque no hubo tanta vergüenza. Había gente que la apoyó y lo decía. En Argentina no, preguntabas y aparentemente $95 \%$ de la población estaba en contra. Esto creo que era falso. Así como el gobierno dictatorial tuvo apoyo civil, ese apoyo civil quedó escondido, avergonzado y ahora está resurgiendo de alguna manera. Se está transparentando y eso que ya estaba, ese fascismo social estaba y ahora se ve, es más visible.

\section{Entrevistadoras:}

Y creo que incluso porque ustedes tuvieron una dictadura peor, más larga que la nuestra.

\section{Gabriel Anitua:}

Peor y perdidosa también. Como tuvo la guerra de Malvinas tuvimos una derrota. Derrota no, hecha, lamentablemente, no por nosotros mismos argentinos por todo ese contexto. Pero que avergonzaba incluso a los que la apoyaban tácitamente. Eso en Brasil me parece que no fue tan así.

\section{Entrevistadoras:}

Sí. Y acá siento que ustedes estudiaron mucho más la dictadura. Todos saben cómo sufrieron, hasta hoy las madres de la plaza de mayo están ahí todos los jueves. Ustedes hablan de eso todo el tiempo, es una memoria viva. Eso nunca salió de la mente de los argentinos. Siempre hay nuevas noticias de nuevos nietos encontrados y hay como que una conmemoración.

\section{Gabriel Anitua:}

La propia investigación y el juzgamiento penal tiene mucho que ver en eso. Yo discuto mucho de los efectos de la pena y en eso comparto también con el escepticismo de Zafaroni. Pero creo que tiene un efecto muy importante el juicio penal. El juicio de los años 1980 contra las juntas militares y los más recientes tienen efectos importantes en sectores de la población. En los 1980 era de gente más grande, pero los más recientes y más jóvenes es muy notable como perciben y como hacen esa memoria de la historia y como perciben negativamente a la dictadura y a los militares y a los civiles que fueron cómplices. Y me parece que ese efecto de la visibilización, de la publicidad del juicio es muy importante. Eso en Brasil no lo tuvieron. Claro, pocos países lo tuvieron.

\section{Entrevistadoras:}

Sí, claro. Tuvimos hace poco, solo con Dilma, la Comisión de la verdad que era hablar con los genocidas sobre que hicieron con los desaparecidos, donde estaban, que pasó. 


\section{Gabriel Anitua:}

Sí, pero eso no tiene los efectos como un juicio de verdad que se determina con un castigo y que puedan defenderse, por lo tanto.

\section{Entrevistadoras:}

Sí. En realidad, una vez que no tuvimos la investigación y el juicio los crímenes continuaron a suceder. O sea, la democracia empezó, pero las personas que se opusieron a la dictadura militar siguieron desapareciendo. Entonces es un caso oscuro en Brasil, mismo después de la comisión de la verdad.

\section{Gabriel Anitua:}

Oscura y muy compleja porque es un país también mucho más grande. Seguramente las realidades son distintas en un estado que en otro. $\mathrm{Y}$ por eso no me atrevo a hablar mucho de algo que sé que me excede.

\section{Entrevistadoras:}

En Brasil hoy vivimos en un fenómeno complejo de prender a los que tienen más plata e influencia. Políticos, dueños de constructoras, personas que fraudaron licitaciones, que es la llamamos "Operación Lava a Jato". Y eso pasa una idea de que ahora la justicia funciona una vez que no son solos los más miserables y negros los que son presos. Me gustaría saber que piensas de ese tipo de fenómeno.

\section{Gabriel Anitua:}

Creo que tiene a ver con esa nueva dimensión comunicacional de la democracia, que deja de pensar en clases sociales e intereses concretos y apela a la gente, al vecino, a estos poco definidos grupos, que pueden corresponderse con una clase media que se indigna. $Y$ se indigna porque se considera víctima "Nosotros somos víctimas. Victimas de los pobres que nos roban, que nos futran, y también somos victimas de los ricos, de los políticos y sobre todo de las clases empresariales que también nos roban por tema de impuestos." Esto debería denunciarse como una mentira. Yo creo que una tarea importante de la criminología es también denunciar esa mentira evidentemente propiciada por los medios de comunicación para adular a su público, su publico mayoritario que es la clase media. Y es una mentira, porque es falso que todos los pobres delinquen por la pobreza y es falso también que todos los sectores más empoderados de la política, pero también los sectores económicos delincan. Y sobre todo es mentira que la clase media no delinca y solo sea víctima. Acá tenemos siempre esto de mostrar que todo tipo de delito donde la clase media no solo no es víctima, sino que es victimaria. A ver, como los delitos de tránsito ¿Quienes cometen los delitos de tránsito, los culposos? Los que tienen automóviles, no son los pobres, ni los ricos tampoco. ¿Quienes cometen los delitos de género? Todas las clases sociales y especialmente las clases medias. Delitos económicos también. Claro que es otra dimensión de los de Lava a Jatoi en números de reales, pero todas las clases medias brasileras y argentinas también se orgullecen de pagar lo menos posible. Dicen "no me des esta factura y yo te pago en efectivo". Es necesario empezar a denunciar esa supuesta inocencia o victimización de la clase media me parece que es una tarea interesante del punto de vista académico, pero también importante del punto de vista político. Esto de decir, como dijo Sutherlandii en su momento, cuando habló del delito de cuello blanco, "Bueno, el delincuente puede ser cualquiera de nosotros." No hay una determinación, ni de los pobres ni de los ricos para hacerlos delincuentes. Empezamos a estudiarlos más como sociedad también. Sobre todo, para evitar las 
soluciones fáciles. El mayor peligro del poder penal, es presentarse como una solución sencilla y fácil para todos los problemas. Esto es lo que dicen los medios de comunicación y que aceptan las clases medias: "que vayan todos presos!" y todos presos para qué? ¿Qué solución política es esa? Empezar a denunciar el poder penal como una falacia. Como algo que no soluciona ni todos los problemas ni ningún problema. Y todo eso es complicado porque también hay que dirigirse a esa clase media que es muy hipócrita, que no quiere enterarse de las realidades ni sentirse participando del problema. Quiere sentirse victima y reclamar. Hacer un reclamo constante a no se sabe bien quien y señalando siempre con el dedo a los chivos expiatorios. Normalmente son los pobres y siguen siendo los pobres quienes mueren. Pero, ahora les toca a algunos más o menos poderosos. Algunos mismo que pocos, y además los que pierden dentro de las internas, los políticos que perdieron con otros políticos, los empresarios que perdieron frente a otros empresarios. Les llega a estos otros sectores probablemente con esta misma lógica de buscar a ese chivo expiatorio, de limpiarnos la culpa a todos los demás. Eso que está bueno de denunciar y enfrentar a esa lógica punitiva.

\section{Entrevistadoras:}

Sí. Y eso pasa en Brasil. Las personas creen que una vez que prendemos a los ricos ahora la justicia funciona, entonces vamos a prender más y más. Pero no es eso, lo que pasa es que cuando prendemos a un rico podremos prender a mil pobres.

\section{Gabriel Anitua:}

Mucho más, mucho más. Esto es un hecho novedoso como la justicia también entra en esa lógica de legitimarse en la indignación, en los discursos de los medios de comunicación, en lo que reclaman las clases medias y en definitiva en la trampa del poder punitivo. La justicia cae en esa trampa. También su objeto de estudio, la justicia penal es un objeto de la participación política, y no es eso lo que tiene que hacer. Eso al final no los vale. Pareciera legitimarlo, pero al final no los va a legitimar. No están en la situación de la Italia en los 1990, Lava a Jato no es Mani Puliteiii. Eso al final va a terminal mal, también para los propios jueces. Tengan cuidado, esa idea de cautela es importante. Una solución rápida parece efectiva y al poco tiempo va a tener inconvenientes para la propia idea de la legitimación de la justicia. Porque no tiene más que pies de barro, no tiene bases firmes. No va a solucionar ningún problema.

\section{Entrevistadoras:}

Bueno, ahora te hago una pregunta sobre las manifestaciones que hubo en Argentina el 2017. Ustedes tenían la política del $2 \times 1$ a respecto de las prisiones preventivas y ese año tuvieron manifestaciones populares muy grandes para que eso no fuera aplicable a los genocidas de la dictadura en los crímenes de lesa humanidad. ¿Podrías explicarnos que es esa política y por qué la población no aceptó que mantuviesen esa aplicación y porque al gobierno Macri le interesaba ponerla en práctica ahora?

\section{Gabriel Anitua:}

Eso tuvo vigente por muy poco tiempo justamente en los años 90, cuando enfrentamos la primera crisis de sobrepoblación, una solución pensada por el gobierno de Carlos Menem para reducir ese número de presos, y sobre todo de presos preventivos, fue castigar de alguna forma el Estado y premiar a los que fueron arrestados en prisión preventiva con esa ley que les computaba a doble el tiempo 
pasado en la prisión después de dos años de prisión preventiva. Dos años de prisión preventiva o provisional era aceptable. Y si pasa más de dos años en prisión preventiva se computaba doble. Era un intento de conseguir bajar el número de presos en los años 1990. Pero rápidamente se dio de baja, la ley no continuó por los reclamos de la lógica punitiva, que incluso quería más presos. El efecto directo de esa derogación fue que rápidamente el número de presos entre los años 1998 - 2004 creció muchísimo. Y luego hubo otras decisiones para bajar el número de presos. Entonces esa ley se quedó ahí en los 1990 y benefició a algunos presos que estaban presos en ese momento, pero ya no más después. La trampa que ahora quisieron articular muchos ajuiciados por los delitos de lesa humanidad es que dicen "esa ley a mi me corresponde porque yo en los años 1990 ya había cometido el delito. Porque los delitos son de los años 1970. Pero yo no estuve preso, pero si me tienen que aplicar eso, porque yo entonces estaba siendo investigado y podría haber sido investigado, porque el crimen es anterior". Eso es un absurdo. Un absurdo total. Pero en algunos casos fue sancionado, llegó a la corte superior de suprema en el año pasado y sancionaran diciendo "Bueno, esto se puede aplicar a este señor" y entonces se reducían los números de las condenas. Ahí también lo más positivo fue la reacción de ambos los sectores de la población, la clase media también salió a la plaza de mayo a decir "iEso no queremos! No queremos arguyes, trampas legales para beneficiar a los genocidas. 2x1 no". Fue como un representante de ese giro que el gobierno claramente quería hacer y que la mayoría social no le dejaron. Ni a la justicia ni al gobierno. Dijeron "Cuidado con este tema que es muy sensible", que parece haberse reducido a ese consenso, pero sigue siendo la amplia mayoría que no quiere indultar o perdonar a los responsables de esa dictadura y genocidio que se llevaron adelante.

\section{Entrevistadoras:}

Y los crímenes de lesa humanidad acá son perpetuos? ¿Los individuos-se van a morir en las cárceles?

\section{Gabriel Anitua:}

Esa es otra discusión acerca de los castigos, porque efectivamente se pueden aplicar beneficios a respecto de las prisiones domiciliares y esa es la vía que está intentando el gobierno ahora. Pero hay gente que se opone a eso porque dicen "Bueno, tiene tanta edad no está bien que mueran en la cárcel. Una vez que muchos de esos miembros de la dictadura murieron en las cárceles". Y ahora están intentando que esto no suceda. Y ahí ya hay relaciones humanistas que los avalan, ya ellos serían menos exigentes. Para mi lo más importante fue el juicio y las condenas que dijeron "Eso que hicieron estuvo muy mal y merecen una condena a la perpetuidad o 40 años". Creo que, si mueren en su casa o no, no me parece tan relevante. Pero entiendo que hay víctimas y que hay sectores sociales a los cuales eso les parece mal. Sobre todo en la comparación "¿Bueno porque a estos si y a nosotros no? A todos los pobres que van a las cárceles y a esos otros que son delitos mas agarrantes no". Si todas las cárceles fueran humanitarias, a todas las mujeres, a los padres que cuidan a los niños, a los ancianos, si todos tuviesen con esas medidas, bueno, entonces probablemente se aplicaría también a los genocidas. Pero parece ser un privilegio para ellos. Pero todo eso es muy complejo incluso para nosotros que no defendemos ninguna utilidad en el castigo diario. La cárcel me da igual, no es que quiero que mueran en una unidad carcelaria. No quiero que muera nadie en la prisión.

\section{Entrevistadoras:}

Gabriel, tanto acá cuanto en Brasil estamos ahora con las discusiones a respecto de la reducción de la mayoridad penal. En Brasil de 18 para 16 años, en este caso 
adolescentes conviven confinados con los demás adultos. Entre las edades de 12 a 18 años ya tenemos las instituciones en donde ponemos los jóvenes encarcelados, pero no se quedan junto a los adultos. Acá ustedes tienen prisiones de adultos a partir de los 18 y para jóvenes a partir de los 16 y ahora intentan bajar para 14 años.

\section{Gabriel Anitua:}

Sí, tenemos un régimen especial, de toda forma. Ya tenemos ese régimen de 16 a 18 años y ahora intentan bajarlo para 14 a 18 años. Yo creo que sí, que es una deuda y estaría bien pensar lo que hacer con esa etapa tan crítica. Solo que normalmente los que están envueltos en conflictos en la calle con la policía son adolescentes, chicos jóvenes, y hay que pensarlo. Pero aquí no se piensa nada. Cada vez más se busca una solución mágica del poder penal, castigándolos como se fueran grandes y ya está. ¿Ya está qué? No es esa la solución. Sí es necesario discutir la cuestión de los niños y las niñas y los adolescentes en conflictos con la policía y con la propia ley, pero no simplificando esa discusión siendo más punitivo y más duros. Eso es disfrazar la discusión. Eso es lo que tiene el poder punitivo con la lógica mediática, política, demagógica, lleva a eso, a pervertir la discusión y a impedirla de hecho.

\section{Entrevistadoras:}

Nos gustaría saber lo que piensas sobre las prisiones privadas, o sea, las aparcerías público-privadas adentro de los complejos penitenciarios y de la seguridad pública. Los los costos de cada preso son mucho más caros pero lo que dicen es que son mejores y menos violentas. Yo sé que en Argentina ustedes aún no tienen esas prisiones, pero ¿qué crees de ese fenómeno del capital privado en la seguridad?

\section{Gabriel Anitua:}

En Argentina no hay cárceles privadas pero el capital privado quiere hacer negocio con todo. $Y$ evidentemente construir cárceles o proveerlas de medicamentos o de alimentos esto es un negocio también y esto existe también en Argentina. Muchas veces están ligados también a la corrupción. Se aseguran ser los proveedores de alimentos para las cárceles, que son estatales, pero los que entregan alimentos no lo son. Y el capitalismo se pretende desligado del Estado, pero siempre está vinculado al Estado y hace los mejores negocios con el Estado, esto también es parte de la lógica de corrupción. ¿Como impedir eso? Básicamente con mayores controles. Sobre las cárceles privadas yo no sé lo que decir, me parece raro ese fenómeno en Brasil porque en Estados Unidos, donde igual hay más controles, me parece que están abandonando ese modelo porque no les pareció un buen negocio. Preferían vender armas, en fin, hacer otros negocios de donde pueda haber mayores ganancias. Si las cárceles privadas van a estar efectivamente controladas yo creo que el capital se va a marchar, no le va a interesar. El problema es cuando puede hacer cualquier cosa, y sobre todo puede aumentarse la violencia porque simplemente es más barato tener menos funcionarios, o que sean menos capacitados, en peores condiciones sanitarias o de alimentos. Este es el peligro de no controlar a esos capitales privados vinculados con esa vocación estatal de castigar.

\section{Entrevistadoras:}

Y la última pregunta sabemos que no hay una respuesta directa y sencilla, pero nos gustaría saber si hoy tuviera que ser responsable por cómo poner en práctica un plan de gestión pública, ¿cuáles piensas que son las medidas más cruciales? 


\section{Gabriel Anitua:}

Yo en verdad sería poco ambicioso. No se puede hacer un programa que solucione todo porque eso es mentira. Si yo fuese un asesor de un político con un discurso de seguridad lo primero que le diría es "No digan que solucionan rápidamente o con una idea genial. No se puede hacerlo. No se puede y va a generar y fraudar expectativas y por lo tanto perder legitimidad. Lo que sí se puede hacer son políticas concretas y pequeñas". Si tenemos un problema en el cual se mueren mucha gente en las carreteras y en las autovías, entonces hay que ponerse un sistema de control de velocidad y eso puede ser que en pocos años reduzca la mortandad, reduzca esa violencia, que es lo que se podría llegar a hacerlo. O hacer política para el uso adecuado de las armas por parte de la policía, eso también es posible. Poner más control, saber que armas utilizan. Lo que se puede hacer son políticas muy centradas, con objetivos concretos sin esa ambición de "quiero solucionarlo a todo" porque eso es magia, es falso, eso no existe. Se me ocurren muchas cosas, esas son dos ideas no más, pero se me ocurren otras más destinadas muy concretamente a reducir la violencia, que se hayan menos muertes. Buscando reducir la violencia, en materia penitenciaria hay muchas cosas que se puede hacer, claro. Reducir el número de presos va a implicar una mejora, pero también puede haber otras mejoras como de los sistemas educativos en las cárceles, impedir traslados arbitrarios, mejorar la alimentación, los programas de atención psiquiátrica, hay muchas cosas para hacer. Pero, ya digo, tienen que ser bien concretas para mejorar todo ese fenómeno de la cuestión criminal.

\section{Entrevistadoras:}

Es eso. Muchas gracias por su entrevista Gabriel.

(Recebido para publicação em fevereiro de 2019)

(Reapresentado em fevereiro de 2019)

(Aprovado para publicação em março de 2019)

\section{Cite esta entrevista}

ANITUA, Gabriel, 2019. Entrevista conduzida por Tamires Alves e Gabriela Gusis. Revista Estudos

Políticos: a publicação semestral do Laboratório de Estudos Hum(e)anos (UFF).Rio de Janeiro, Vol.10 |N.1, pp.17-28, maio de 2019.

\section{Notas}

1. La operación que está ahora en curso en Brasil que trata de los desvíos de dinero entre políticos y grandes empresarios.

2. Libro de Cuello Blanco de Sutherland. Poner referencia completa.

3. Manos Limpias proceso judicial realizado en Italia el 1992, investigó políticos, empresarios, pero principalmente los sectores más a la izquierda. Arrestó a 2993 personas y llevó el país a una de sus 
mayores crisis económicas y políticas ya enfrentadas. 